\title{
Micro-structured Materials for the Removal of Heavy Metals using a Natural Polymer Composite
}

Eny Kusrini ${ }^{1}{ }^{*}$, Karina Ayuningtyas ${ }^{1}$, Dias Puspitaning Mawarni' ${ }^{2}$, Lee D. Wilson ${ }^{3}$, Muhammad Sufyan ${ }^{4}$, Arif Rahman ${ }^{5}$, Yohanes Eko Adi Prasetyanto ${ }^{6}$, Anwar Usman ${ }^{7}$

${ }^{1}$ Department of Chemical Engineering, Faculty of Engineering, Universitas Indonesia, Kampus Baru UI Depok, 16424, Indonesia

${ }^{2}$ Department of Medical, Faculty of Medical, Universitas Pembangunan Nasional Veteran Jakarta, Jakarta 12450, Indonesia

${ }^{3}$ Department of Chemistry, University of Saskatchewan, 110 Science Place, Room 156 Thorvaldson Building, Saskatoon, Saskatchewan, Canada S7N 5 C9

${ }^{4}$ Department of Computer Science, Faculty of computer science and Information Technology, Virtual University of Pakistan, Lahore, Pakistan

${ }^{5}$ Department of Chemistry, Faculty of Mathematic and Natural Sciences, Universitas Negeri Jakarta, Jakarta Timur 13220, Indonesia

${ }^{6}$ Faculty of Medicine and Health Sciences, Universitas Katolik Indonesia Atma Jaya, Jalan Pluit Raya 2, Jakarta 14440, Indonesia

${ }^{7}$ Department of Chemistry, Faculty of Science, Universiti Brunei Darussalam, Jalan Tungku Link, Gadong BE1410, Negara Brunei Darussalam

\begin{abstract}
In this study, a precipitation method was employed to prepare a synthetic hydroxyapatite (HAP)/chitosan (CHN) composite by the modification of synthetic HAP with CHN. The HAP/CHN composite was characterized by Fourier transform infrared (FTIR) spectroscopy and scanning electron microscopy equipped with energy-dispersive X-ray spectroscopy (SEM-EDX). Furthermore, the HAP/CHN composite in a 1:1 ratio (wt.\%) was investigated as an adsorbent for the removal of heavy metals ions (such as $\mathrm{Cr}^{6+}, \mathrm{Cd}^{2+}$ and $\mathrm{Zn}^{2+}$ ) from simulated wastewater. Adsorption experiments were conducted in batch mode at room temperature. In addition, the effect of process conditions, such as contact time, was evaluated. Kinetic data were well-described by the pseudo-second-order kinetic model, where adsorption was governed by the intraparticle diffusion model. The HAP/CHN composite demonstrated potential utility as an adsorbent for the removal of heavy metals from an aqueous solution, with the highest maximum adsorption capacities of 39.3, 30.8 and $29.9 \mathrm{mg} / \mathrm{g}$ for $\mathrm{Cr}^{6+}, \mathrm{Cd}^{2+}$ and $\mathrm{Zn}^{2+}$, respectively. The HAP/CHN composite materials with variable structure and composition exhibited remarkably different adsorption properties and potential applicability for industrial applications due to the material cost-effectiveness.
\end{abstract}

Keywords: Adsorption; Chitosan; Composite; Micro-structured materials; Simulated wastewater

\section{Introduction}

Heavy-metal contamination poses a serious problem for the environment and human health. Industries such as mining, smelting, batteries, and chemical production release certain heavy metals into surface and groundwater supplies, resulting in negative

${ }^{*}$ Corresponding author's email: ekusrini@che.ui.ac.id, Tel.: +62-21-7863516 ext. 204, Fax: +62-21-7863515 doi: 10.14716/ijtech.v12i2.4578 
environmental effects (Duan et al., 2020). In recent years, adsorption-based methods have been employed to investigate the removal of heavy metal ions from wastewater (Gupta et al., 2012; Salah et al., 2014; Zhang et al., 2018; Vieira et al., 2019; Kusrini et al., 2020a; Kusrini et al., 2020b). Adsorption is typically employed in industries due to its high efficiency and cost-effectiveness (Kusrini et al., 2019a; Kusrini et al., 2019b; Kusrini et al., 2019c). Some polymers and synthetic materials, such as chitosan (CHN), hydroxyapatite (HAP), activated carbon and zeolites have been reportedly used as adsorbents to remove heavy metal ions from aqueous media (Gupta et al. 2012; Salah et al., 2014; Zhang et al., 2018; Vieira et al., 2019). HAP has been reported to exhibit high removal capacities for divalent heavy-metal ions (Corami et al., 2007). To improve the HAP adsorption performance for heavy-metal species, a composite of HAP with some polymers can be prepared, including HAP/polyacrylamide (HAP/PAAm), HAP/polyurethane (HAP/PU) and $\mathrm{HAP} /$ polyvinyl alcohol (HAP/PVA) (Dong et al., 2010). In addition, the adsorption of $\mathrm{Cu}^{2+}$ and $\mathrm{Cr}^{6+}$ on biopolymers such as CHN was also reported (Schmuhl et al., 2001). HAP-CHN composites have been reported for the removal of $\mathrm{Fe}^{3+}$ (Kousalya et al., (2010), $\mathrm{Pb}^{2+}, \mathrm{Co}^{2+}$ and $\mathrm{Ni}^{2+}$ (Gupta et al., 2012), $\mathrm{Cd}^{2+}$ (Salah et al., 2014), $\mathrm{Pb}^{2+}$ (Zhang et al., 2018) and $\mathrm{Cr}^{6+}, \mathrm{Cd}^{2+}$ and $\mathrm{Zn}^{2+}$ (Kusrini et al., 2013). Recently, HAP/CHN-layered composites have been reported for the removal of lead ions from continuous-flow wastewater (Zhang et al., 2020); in that study, HAP is extracted from Tilapia fish and then a composite with CHN is prepared to remove $\mathrm{Pb}^{2+}$ from wastewater (Liaw et al., 2020). A CHN/HAP composite nanofiber membrane for the adsorption of $\mathrm{Pb}, \mathrm{Co}$ and $\mathrm{Ni}$ ions from an aqueous solution has been reported (Aliabadi et al., 2014). The presence of amine (- $\left.\mathrm{NH}_{2}\right)$ and hydroxyl $(-\mathrm{OH})$ groups in $\mathrm{CHN}$ can serve as active sites for the removal of heavy metals from aqueous media via adsorption (Gupta et al. 2012; Aliabadi et al., 2014; Kusrini et al., 2019a).

Chromium (Cr) is well known to be the main additive in stainless steel that inhibits corrosion. As a result, stainless steel has a high market value due to its corrosion resistance and hardness. Several applications of stainless steel are known as a result of the electroplating industry. $\mathrm{Cr}^{3+}$ is not considered toxic; however, hexavalent chromium $\left(\mathrm{Cr}^{6+}\right)$ is highly toxic and carcinogenic. Zinc $(\mathrm{Zn})$ is also most commonly used due to its anticorrosion properties as well as for galvanization, whereas cadmium (Cd) is used for corrosion-resistant plating on steel and to colour glass, as well as to stabilize plastic. Cd is toxic, which is replaced by metal hydride or lithium-ion batteries in the battery industry. Previously, HAP modified with CHN in a 30:70 (wt\%) ratio for the removal of heavy-metal ions from aqueous media has been reported (Kusrini et al., 2013). In this study, synthetic HAP was modified with $\mathrm{CHN}$ in a 1:1 ratio. In addition, a new material adsorbent was developed as a composite material that contains CHN and synthetic HAP. As well, its synergistic properties were investigated for the removal of heavy-metal ions (such as $\mathrm{Cr}^{6+}$, $\mathrm{Cd}^{2+}$ and $\mathrm{Zn}^{2+}$ ) from an aqueous solution to evaluate the optimum removal efficiency. Notably, an equal composition of HAP and CHN was investigated to observe the effect of the weight ratio of HAP and CHN and to examine the effect of carboxyl and hydroxyl functional groups from the natural polymer CHN on the composite surface.

\section{Experimental}

\subsection{Materials}

$\mathrm{Zn}\left(\mathrm{NO}_{3}\right)_{2} \cdot 4 \mathrm{H}_{2} \mathrm{O}$ was purchased from Merck (Germany). CHN powder with a deacetylation degree of $90.77 \%$ was purchased from PT Biotech Surindo (Indonesia). All of the materials were used as received without further purification. 
2.2. Synthesis of the Micro-structured HAP/CHN Composite in a 1:1 Ratio (wt.\%) by Precipitation

The 1:1 (wt.\%) HAP/CHN composite was synthesized by precipitation and a mixing method according to a previous study (Kusrini et al., 2013). First, synthetic HAP was prepared by mixing phosphoric acid with calcium hydroxide in a stoichiometric ratio of 1.67. The formed precipitate was filtered and dried at $100^{\circ} \mathrm{C}$ for $12 \mathrm{~h}$. Then, a CHN solution was prepared in distilled water at $\mathrm{pH} 6.5$ with mixing under stirring for $6 \mathrm{~h}$. Next, the resulting precipitate was maintained for $15 \mathrm{~h}$, and the suspension was filtered and dried at $100^{\circ} \mathrm{C}$ for $12 \mathrm{~h}$. The HAP/CHN composite was ground to obtain a powdered composite. Figures $1 \mathrm{a}$ and $1 \mathrm{~b}$ shows the synthetic scheme of HAP and the 1:1 (wt.\%) HAP/CHN composite.

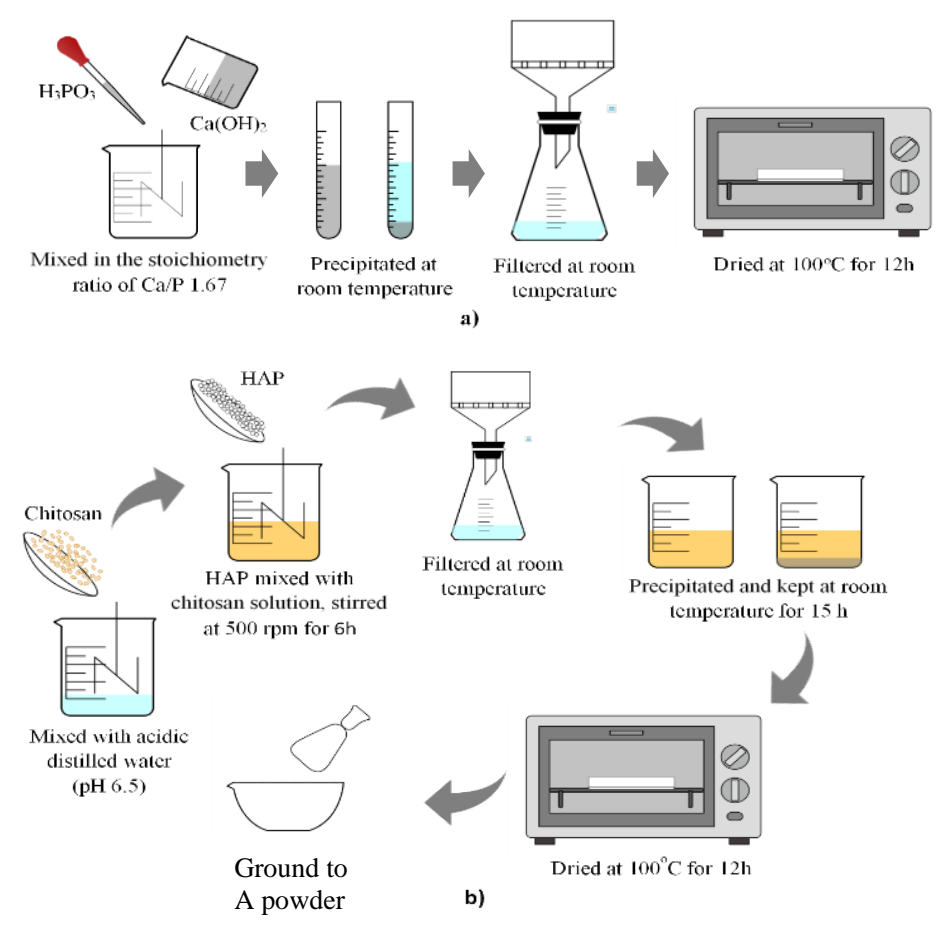

Figure 1 Schematic illustration of the synthesis of HAP (a) and 1:1 (wt.\%) HAP/CHN composite (b)

\subsection{Characterization}

FTIR spectra were recorded against a blank $\mathrm{KBr}$ background at $4000-400 \mathrm{~cm}^{-1}$ on a Perkin-Elmer 2000 FTIR system. The morphology and elemental composition of the samples were determined by scanning electron microscopy (SEM)-energy-dispersive X-ray spectroscopy (EDX).

\subsubsection{Adsorption experiments in the batch mode}

First, a stock solution (1000 ppm) for each metal ion was prepared by dissolving each of $\mathrm{Cd}\left(\mathrm{SO}_{4}\right) \cdot 8 \mathrm{H}_{2} \mathrm{O}$ (2.282 g), $\mathrm{K}_{2} \mathrm{Cr}_{2} \mathrm{O}_{7}\left(2.827 \mathrm{~g}\right.$ ) and $\mathrm{Zn}\left(\mathrm{NO}_{3}\right)_{2} \cdot 4 \mathrm{H}_{2} \mathrm{O}$ (3.997 g) in distilled water. Each solution was adjusted to a concentration of $333.3 \mathrm{ppm}$ for each heavy-metal ion species. Adsorption studies for the removal of $\mathrm{Cr}^{6+}, \mathrm{Cd}^{2+}$ and $\mathrm{Zn}^{2+}$ in simulated wastewater were performed in a batch system. A solution $(100 \mathrm{~mL})$ containing $\mathrm{Cr}^{6+}, \mathrm{Cd}^{2+}$ and $\mathrm{Zn}^{2+}$ was prepared, and $0.5 \mathrm{~g}$ of the HAP/CHN adsorbent was added and mixed under stirring for $5,10,20,30$ and $45 \mathrm{~min}$ at $500 \mathrm{rpm}$ to attain equilibrium conditions. The suspension was filtered using Whatman filter paper, where the $\mathrm{Cr}^{6+}, \mathrm{Cd}^{2+}$ and $\mathrm{Zn}^{2+}$ concentration levels were measured by inductively coupled plasma-atomic emission spectroscopy (ICP-AES). 


\subsubsection{Adsorption isotherm}

Adsorption isotherm data were analysed by the Langmuir isotherm model that accounts for monolayer surface adsorption (Kusrini et al., 2019a; Kusrini et al., 2019b). The Langmuir isotherm model, $\mathrm{Q}_{\mathrm{e}}$, was fitted using a linearized form, according to Equation 1.

$$
1 / Q_{e}=1 / Q_{m} K_{L} \times 1 / C_{e}+1 / Q_{m}
$$

where $\mathrm{Q}_{\mathrm{m}}$ is the maximum monolayer adsorption capacity, and $\mathrm{K}_{\mathrm{L}}$ is the Langmuir equilibrium constant.

\subsubsection{Adsorption kinetics}

By varying the contact time under optimum conditions, $Q_{t}$ was obtained, and kinetic data were analysed using Lagergren pseudo-first order (Lanregren, 1889) and pseudosecond order (Robati, 2013) kinetic models, which were expressed in Equations 2 and 3, respectively. Kinetic data were investigated using the Weber-Morris intraparticle diffusion model (Weber and Morris, 1963) with Equation 4. Accordingly, in these simulations, the time-dependent adsorption efficiency was fitted by Equations 2-4 (Kusrini et al., 2019b).

$$
\begin{aligned}
& \ln \left(Q_{e}-Q_{t}\right)=\ln Q_{e}-k_{1} t \\
& t / Q_{t}=1 / k_{2} Q_{e}^{2}+t / Q_{e} \\
& Q_{t}=k_{i} t^{1 / 2}+C
\end{aligned}
$$

where $Q_{t}$ is the time-dependent sorption, $k_{1}$ and $k_{2}$ are the pseudo-first and pseudosecond order rate constants, respectively and $k_{i}$ is the intraparticle diffusion rate constant. A plot of $Q_{t}$ versus $\mathrm{t}^{1 / 2}$ yields a straight line, with a gradient $k_{i}$ and an intercept (C) if the adsorption mechanism follows intraparticle diffusion.

\section{Results and Discussion}

\subsection{FTIR Studies}

Figures 2a-2c shows the FTIR spectra of the natural polymer CHN, synthetic HAP and HAP/CHN composite adsorbent. An absorption peak at $3416 \mathrm{~cm}^{-1}$ was observed in the FTIR spectrum of synthetic HAP (Figure 2b), corresponding to the hydroxyl $(-\mathrm{OH})$ stretching vibrations. Absorption peaks at 602 and $562 \mathrm{~cm}^{-1}$ corresponded to the $\mathrm{PO}_{4}{ }^{3-}$ bending vibrations, while a band at $1024 \mathrm{~cm}^{-1}$ corresponds to the $\mathrm{PO}_{4}{ }^{3-}$ stretching vibrations. An absorption band at $3408 \mathrm{~cm}^{-1}$ relates to $\mathrm{OH}$ stretching vibrations (Figure $2 \mathrm{a}$ ).

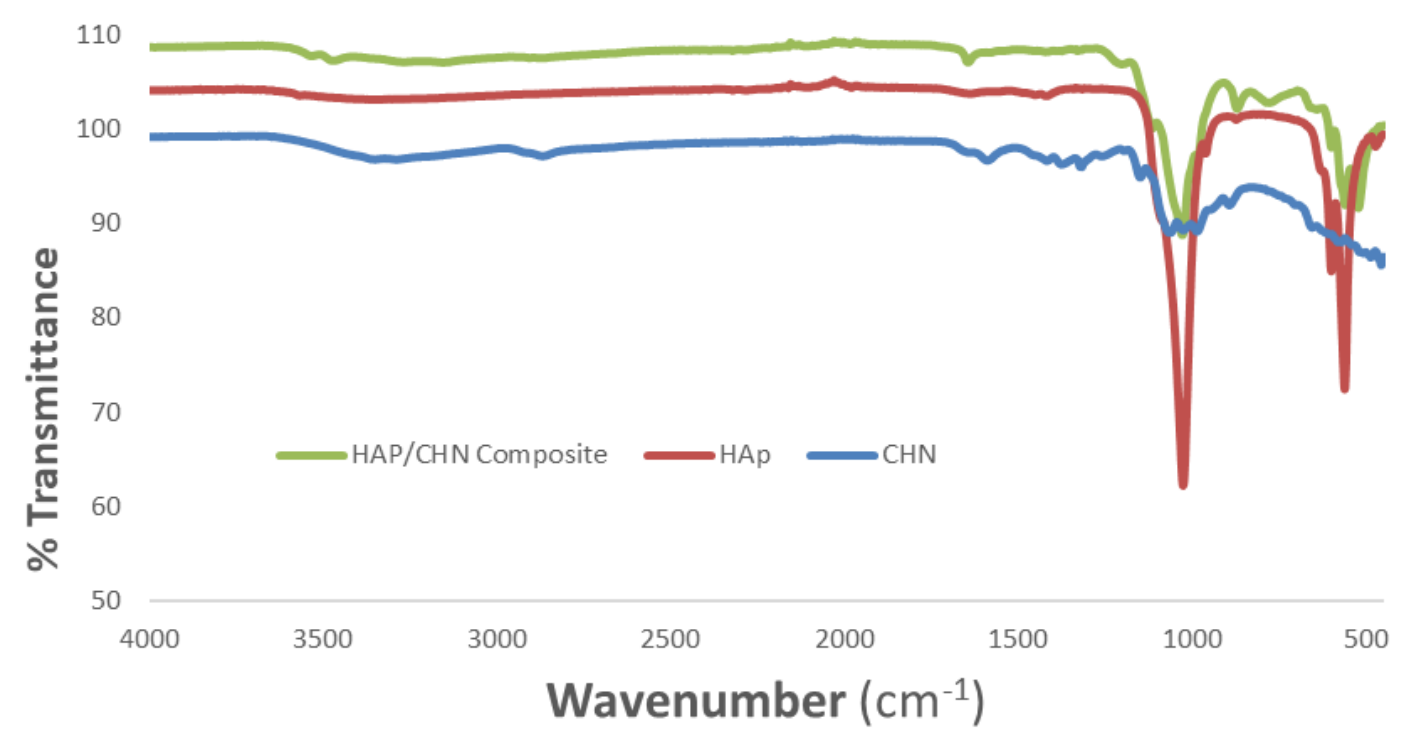

Figure 2 FTIR spectra of CHN (a), synthetic HAP (b) and the HAP/CHN composite (c) 
The frequency of this band was greater than that observed for the absorption band corresponding to the $\mathrm{OH}$ stretching vibrations of $\mathrm{CHN}$ at $3343 \mathrm{~cm}^{-1}$, as reported elsewhere (Kusrini et al., 2015a). In addition, bending vibrations of the amine (-NH) group were observed at $1633 \mathrm{~cm}^{-1}$. The comparison of the FTIR spectra of synthetic HAP, CHN and its composite revealed a shift in the absorption band, i.e. mainly $-\mathrm{OH},-\mathrm{NH}$ and $\mathrm{PO}_{4}{ }^{3-}$ groups were shifted to 3449,1560 and $1034 \mathrm{~cm}^{-1}$, respectively, indicating that bonding occurs between HAP and CHN to afford an HAP/CHN composite. Additional discussion regarding the interactions between the HAP/CHN composite and heavy-metal ions via ionic and coordinate covalent bonding will be described in the adsorption discussion (vide infra).

\subsection{Morphology and Composition Studies}

SEM images were recorded to examine the surface morphology of CHN, synthetic HAP and the HAP/CHN composite. Figures 3a-3c shows the SEM images of CHN, synthetic HAP and the HAP/CHN composite.

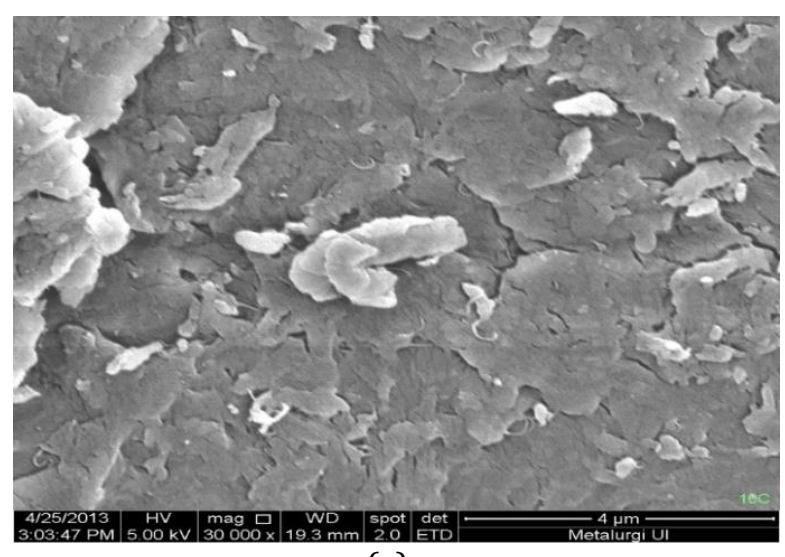

(a)

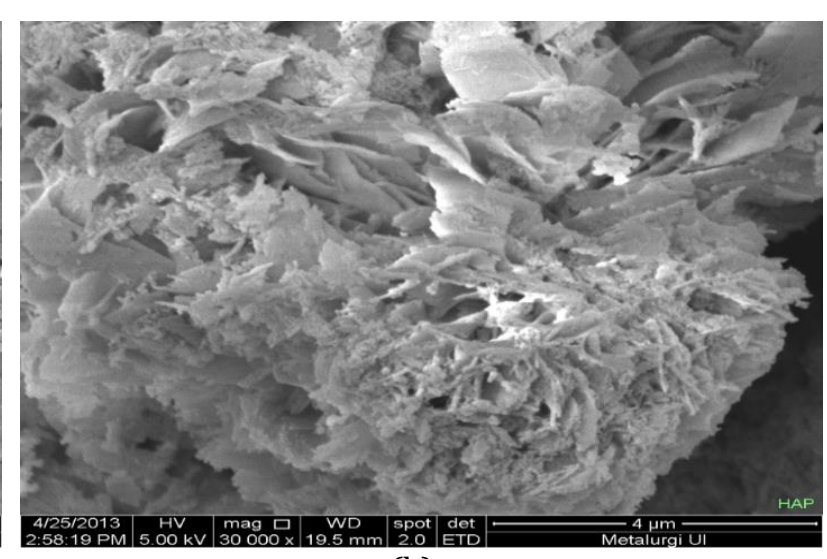

(b)

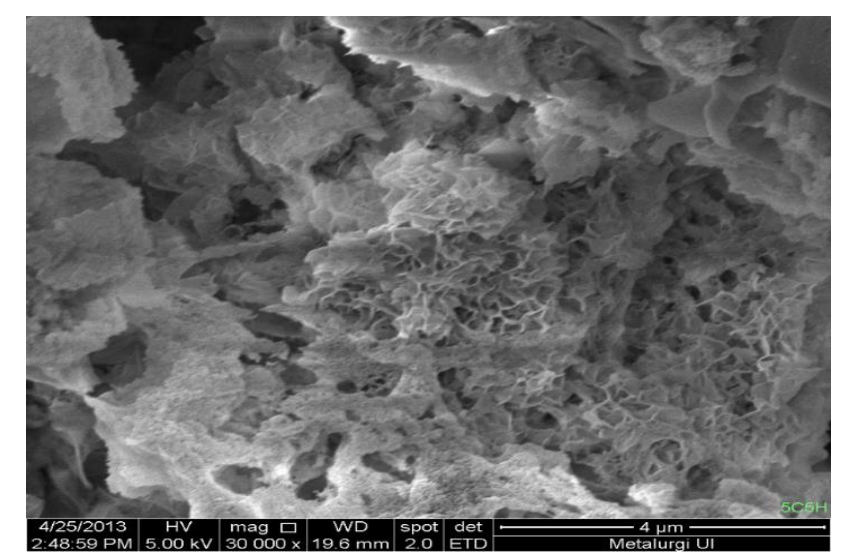

(c)

Figure 3 SEM images of CHN (a), synthetic HAP (b), and the HAP/CHN composite in a 1:1 (wt.\%) ratio at a $30,000 \times$ magnification (c)

CHN exhibited a flat surface comprising stacks of thin overlapping layers. CHN apparently exhibited a flake-like layered structure with variable sizes. Similar observations have been reported by Kusrini et al. (2015b) and Usman et al. (2018) for commercially sourced CHN, exhibiting irregular blocks with a size of 1-100 $\mu \mathrm{m}$. Meanwhile, the synthetic HAP surface was porous and thinly twisted similar to a nest-like structure. Synthetic HAP apparently exhibited hybrid petal-like and dendritic structural features throughout. The SEM image of the HAP/CHN composite revealed features that differed to those of CHN and synthetic HAP. 
The brittle composite revealed significant porosity and holes with a nest structure. The HAP/CHN composite apparently exhibited the same features as those of HAP, albeit with a more pronounced porosity throughout the adsorbent material structure. The composite exhibited a combination of micro-structural features that are intermediate to those observed for CHN and synthetic HAP components. Several porous micro-structural characteristics in the HAP/CHN composite are anticipated to provide good textural characteristics, with a favourable adsorption capacity for the removal of $\mathrm{Cr}^{6+}, \mathrm{Cd}^{2+}$ and $\mathrm{Zn}^{2+}$ ions. EDX measurement in conjunction with SEM characterization was employed to determine the molar ratio of $\mathrm{Ca} / \mathrm{P}$ of synthetic HAP. EDX measurement of synthetic HAP confirmed the presence of Ca, $\mathrm{P}$ and $\mathrm{O}$. According to the molecular formula of standard and pure HAP, the theoretical Ca/P molar ratio is 1.67 (Kusrini and Sontang, 2012). However, the average Ca/P ratio of synthetic HAP was 1.53 . The lower $\mathrm{Ca} / \mathrm{P}$ ratio of synthetic HAP (1.53) indicated that it is likely to be more acidic and more soluble. Furthermore, synthetic HAP formed a composite with natural polymer CHN to afford an HAP/CHN composite, the structure of which exhibited hybrid features as well as plate-like and dendritic structural features, with a porosity greater than that of CHN and possibly greater than HAP.

\subsection{Adsorption of Heavy Metals using a 1:1 Ratio (Wt.\%) of the HAP/CHN Composite}

Figure 4 shows the effect of contact time in the range of 5-45 min for the removal of $\mathrm{Cr}^{6+}, \mathrm{Cd}^{2+}$ and $\mathrm{Zn}^{2+}$ from an aqueous solution by using the HAP/CHN composite. At contact times of 5 and $45 \mathrm{~min}$, the removal (\%) of $\mathrm{Cr}^{6+}$ was in the range of $51.13 \%$ to $58.99 \%$; whereas the removal of $\mathrm{Cd}^{2+}$ was in the range of $36.1 \%$ to $46.12 \%$ and the removal of $\mathrm{Zn}^{2+}$ ion was in the range of $36.31 \%$ to $44.77 \%$. The removal efficiency increased by $8-10 \%$ at a contact time in the range of 5 to $45 \mathrm{~min}$. At a contact time in the range of $0-5 \mathrm{~min}$, significant adsorption of heavy metals was mainly observed, and the removal of $\mathrm{Cr}^{6+}, \mathrm{Cd}^{2+}$ and $\mathrm{Zn}^{2+} \mathrm{did}$ not significantly change after $30 \mathrm{~min}$. Similar trends have been reported for the timedependent removal of lead, cobalt and nickel (Aliabadi et al., 2014). Therefore, the equilibrium time for subsequent experiments used a 30-min time interval.

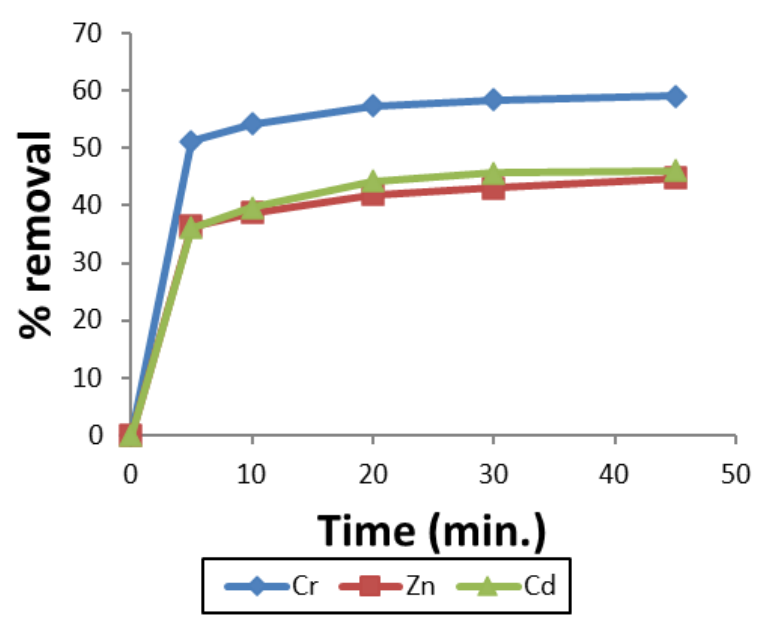

Figure 4 Effect of contact time on the adsorption of heavy-metals ions $\left(\mathrm{Cr}^{6+}, \mathrm{Cd}^{2+}\right.$ and $\left.\mathrm{Zn}^{2+}\right)$ on the HAP/CHN composite at a ratio of $1: 1 \mathrm{wt} . \%$

For comparison, the removal of $\mathrm{Cr}^{6+}, \mathrm{Cd}^{2+}$ and $\mathrm{Zn}^{2+}$ was examined using a 3H7C composite adsorbent composite, with metal-ion removal efficiencies of 73.42, 60.31 and $55.99 \%$, respectively (Kusrini et al., 2013). These heavy-metal ion removal efficiencies were better that those obtained by using the HAP/CHN composite, with removal efficiencies listed in parentheses: $\mathrm{Cr}^{6+}(58.99 \%), \mathrm{Cd}^{2+}(46.12 \%)$ and $\mathrm{Zn}^{2+}(44.77 \%)$. In this study, results 
revealed that the adsorption capacity of different heavy-metal ions are listed in descending order: chromium $>$ cadmium $>$ zinc. This trend is related to the differences in the radii of the hydrated ionic metal ions. By comparison, the heavy-metal ion removal efficiencies (in parenthesis) were obtained using pure synthetic HAP as follows: $\mathrm{Cr}^{6+}(14.02 \%), \mathrm{Cd}^{2+}$ (44.8\%) and $\mathrm{Zn}^{2+}$ (42.91\%). The atomic radii of $\mathrm{Cr}, \mathrm{Cd}$ and $\mathrm{Zn}$ are 128, 134 and $151 \mathrm{pm}$, while their corresponding covalent radii are $139 \pm 5,144 \pm 9$ and $122 \pm 4 \mathrm{pm}$. Cr exhibits the highest charge density among the ions, where the cavity and pore of the HAP/CHN composite were likely more suitable for the adsorption of $\mathrm{Cr}^{6+}$ within the pores and surface sites of the HAP/CHN composite. The trend in adsorption is related to the charge density of each ion, where chromium was removed only by CHN. The removal of $\mathrm{Cd}^{2+}$ and $\mathrm{Zn}^{2+}$ was independent of the $\mathrm{CHN}$ content by comparing with HAP as the adsorbent. This phenomenon can be explained by the better selectivity of the 3H7C adsorbent compared with the HAP/CHN adsorbent composite for the removal of $\mathrm{Cr}^{6+}$. Synthetic HAP is a more functional adsorbent for the removal of heavy metals as synthetic HAP comprises porous characteristics; thus, metals with large and/or small ionic radii can be adsorbed onto the surface. Charge density plays a role in this adsorption since $\mathrm{Zn}$ and $\mathrm{Cd}$ ions are both divalent metals.

Notably, the oxidation number of heavy-metal ions also was not affected by the formation of a complex and/or interaction with active functional groups of CHN for different adsorption abilities of $\mathrm{Cr}^{6+}, \mathrm{Cd}^{2+}$ and $\mathrm{Zn}^{2+}$. The removal efficiency for the heavymetal ions by using the HAP/CHN composite increased due to the presence of amine and hydroxyl groups from the natural polymer CHN (Wu et al., 2010; Kusrini et al., 2013). Both $-\mathrm{NH}_{2}$ and $-\mathrm{OH}$ groups of $\mathrm{CHN}$ were crucial for adsorption (Kusrini et al., 2015a). This adsorption mechanism for metal ions is similar to a previous report (Tomczak, 2011). In addition, the two functional groups were extremely reactive for coordination with metallic ions (Kusrini et al., 2014). Furthermore, CHN in the composite can enhance the removal efficiency of heavy-metal ions due to the presence of suitable functional groups. CHN comprises a primary amine group and two free hydroxyl groups for each glucopyranose unit. Owing to the presence of free amine groups, $\mathrm{CHN}$ is positively charged; hence, it can react with negatively charged polymers and polyanions. Notably, at acidic $\mathrm{pH}$, the free amine group binds to anions by cross-linking, while at alkaline $\mathrm{pH}$, the free amine group can bind to a hydroxyl group or other anions via hydrogen bonding or dipolar interactions. In the presence of other competitor ions in the aqueous solution, the relative removal efficiencies depended on the size and suitable pore dimensions of the effective adsorption sites. Adsorption of metal cations is related to the presence of $-\mathrm{NH}_{2}$ and $-\mathrm{OH}$ groups on the HAP/CHN composite surface. With the increase in the CHN concentration of the composite, greater heavy metal removal was observed for the HAP/CHN composite. This trend concurs with previous results reported for the performance of the $3 \mathrm{H} 7 \mathrm{C}$ adsorbent composite (Kusrini et al., 2013).

\subsection{Adsorption Isotherm}

Table 1 summarizes the maximum monolayer adsorption capacity $\left(Q_{m}\right)$ of each metal. The Langmuir isotherm model was applied to analyse the adsorption mechanism of heavymetal ions on the HAP/CHN composite. Experimental data were plotted and fitted by using the linear relationship given in Equations 1-4. Table 1 also lists the parameters deduced from the best-fit results to the isotherm model for the experimental data.

The $\mathrm{Qm}_{\mathrm{m}}$ values for $\mathrm{Cr}^{6+}, \mathrm{Cd}^{2+}$ and $\mathrm{Zn}^{2+}$ in an aqueous solution were 39.3, 30.8 and 29.9 $\mathrm{mg} / \mathrm{g}$, respectively. The adsorption profiles of heavy metals on the HAP/CHN composite exhibited similar trends, and these metal solutions flowed through the HAP/CHN composite via interlaminar macropores. 
Table 1 Maximum monolayer adsorption capacity values for heavy-metal ions on the HAP/CHN composite

\begin{tabular}{cc}
\hline \multirow{2}{*}{ Heavy metal ions } & $\mathrm{Q}_{\mathrm{m}}(\mathrm{mg} / \mathrm{g})$ \\
\cline { 2 - 2 } & $\mathrm{HAP} / \mathrm{CHN}$ composite \\
\hline $\mathrm{Cr}^{6+}$ & 39.3 \\
$\mathrm{Zn}^{2+}$ & 29.9 \\
$\mathrm{Cd}^{2+}$ & 30.8 \\
\hline
\end{tabular}

The extent of adsorption did not significantly change after $30 \mathrm{~min}$; subsequently, it remained unchanged after 30-45 min. Compared to the HAP/CHN layered composite reported by Zhang et al. (2018), the adsorbed amounts of $\mathrm{Pb}^{2+}, \mathrm{Cd}^{2+}$ and $\mathrm{Hg}^{2+}$ were 296.0, 192.4 and $127.4 \mathrm{mg} / \mathrm{g}$, respectively, after 6 days. Notably, the different structure and composition of the HAP/CHN composite and different times for adsorption resulted in remarkably different adsorption properties. In comparison to the $\mathrm{Qm}_{\mathrm{m}}$ of $\mathrm{Zn}^{2+}$ ion (36.7 $\mathrm{mg} / \mathrm{g}$ ) for a durian rind adsorbent (Ngabura et al., 2018), comparable agreement is noted in Table 1 for the adsorption of $\mathrm{Zn}^{2+}$ on the HAP/CHN composite reported herein.

\subsection{Adsorption Kinetic Studies}

Adsorption kinetics of metals on the HAP/CHN composite were determined by using pseudo-first order (PFO) and pseudo-second-order (PSO) kinetic models, whereas diffusion kinetics were analysed by the Weber-Morris intraparticle diffusion model. Based on the adsorption efficiency, the kinetics of the heavy-metal adsorption was analysed for the HAP/CHN composite adsorbent. Figures $5 \mathrm{a}$ and $5 \mathrm{~b}$ show the linear regression results of the PFO $\left(\mathrm{R}^{2}=0.90,0.84,0.97\right.$ and 1.00$)$ and PSO $\left(\mathrm{R}^{2}=1.00,0.99,0.99\right)$ kinetic models for $\mathrm{Cr}^{6+}$, $\mathrm{Zn}^{2+}$ and $\mathrm{Cd}^{2+}$, respectively. The linear regression results for the kinetics and diffusion models revealed that the adsorption of all heavy-metal ions on the HAP/CHN composite is well described by the PSO model, which indicated is the role of chemisorption (Kusrini et al., 2020c). Heavy-metal ions are assumed to be coordinated to the functional groups of CHN and HAP via favourable coordination and electrostatic interactions. This adsorption behaviour is similar to that of lanthanide using a pectin-activated carbon (Pec-AC) composite (Kusrini et al., 2020c). The ratio of synthetic HAP and CHN did not markedly affect the kinetic results, but the component ratio affected the adsorption efficiency for the heavy-metal ions. The adsorption capacity, $Q_{\mathrm{e}}$ (calc.), values estimated by the PFO and PSO kinetic models were 39.7, 30.1 and $31.4 \mathrm{mg} / \mathrm{g}$, respectively (Table 2). The kinetic estimates were are similar to the experimental $Q_{\max }$ values of $38.9,28.7$ and $30.4 \mathrm{mg} / \mathrm{g}$ estimated at equilibrium by the Langmuir model (Table 1). This result confirmed that the adsorption kinetics of heavy-metal ions on the HAP/CHN adsorbent composite is well described by the PSO kinetic model. The maximum capacity estimated experimentally $\left(Q_{e}\right)$ using the HAP/CHN composite was less than those obtained for the 3H7C composite, with values of 48.5, 35.3 and $39.1 \mathrm{mg} / \mathrm{g}$ for $\mathrm{Cr}^{6+}, \mathrm{Zn}^{2+}$ and $\mathrm{Cd}^{2+}$, respectively (Kusrini et al., 2013).

From the simulation of the intraparticle diffusion rate, the intercept value (C) indicated the thickness of the boundary layer exerts a greater effect (Gupta et al., 2012). Adsorption occurred in two stages. The first stage involved surface adsorption, followed by intraparticle diffusion. Figure 6 shows the intraparticle diffusion model for the adsorption of $\mathrm{Cr}^{6+}, \mathrm{Cd}^{2+}$ and $\mathrm{Zn}^{2+}$ on the HAP/CHN composite. The modified CHN material can enhance the adsorption capacity and removal efficiencies of heavy metal species. Additional studies of the effect of parameters such as temperature, $\mathrm{pH}$ dependence, co-existing ions, on the adsorption performance are underway. 


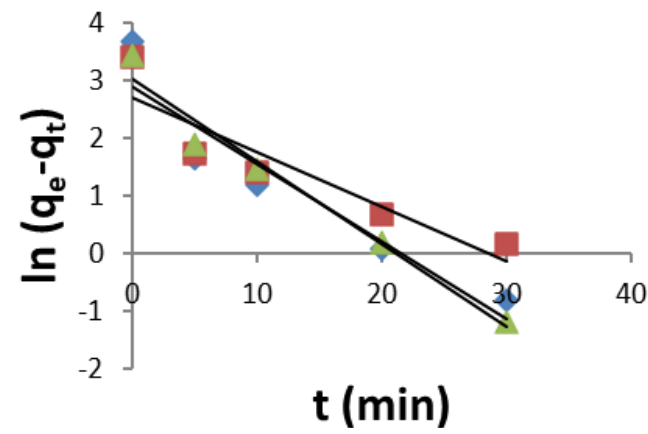

(a)

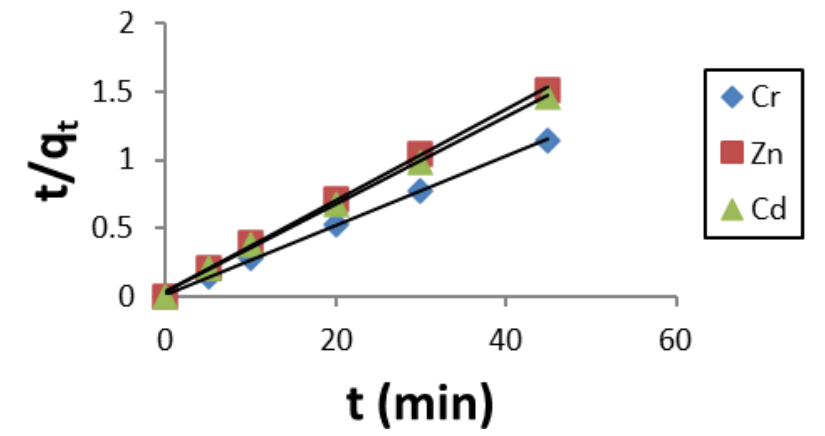

(b)

Figure 5 Pseudo-first-order (PFO) and pseudo-second-order (PSO) kinetic models for the adsorption of heavy metals on the HAP/CHN composite

Table 2 Kinetic parameters of the PFO and PSO models for the adsorption of heavy metals on the HAP/CHN composite

\begin{tabular}{ccccc}
\hline \multicolumn{5}{c}{ Pseudo-first-order (PFO) model } \\
\hline Heavy metal Ion & $\mathrm{Q}_{\mathrm{e}}(\exp )$ & $\mathrm{Q}_{\mathrm{e}}$ (cal.) & $\mathrm{k}_{1}$ & $\mathrm{R}^{2}$ \\
\hline $\mathrm{Cr}^{6+}$ & 38.89 & 18.15 & -0.13 & 0.90 \\
$\mathrm{Zn}^{2+}$ & 28.67 & 14.81 & -0.09 & 0.84 \\
$\mathrm{Cd}^{2+}$ & 30.45 & 20.47 & -0.14 & 0.97 \\
\hline \multicolumn{5}{c}{ Pseudo-second-order (PSO) model } \\
\hline $\mathrm{Cr}^{6+}$ & 38.9 & 39.68 & 0.04 & 1.000 \\
$\mathrm{Zn}^{2+}$ & 28.7 & 30.12 & 0.03 & 0.998 \\
$\mathrm{Cd}^{2+}$ & 30.4 & 31.35 & 0.03 & 0.999 \\
\hline
\end{tabular}

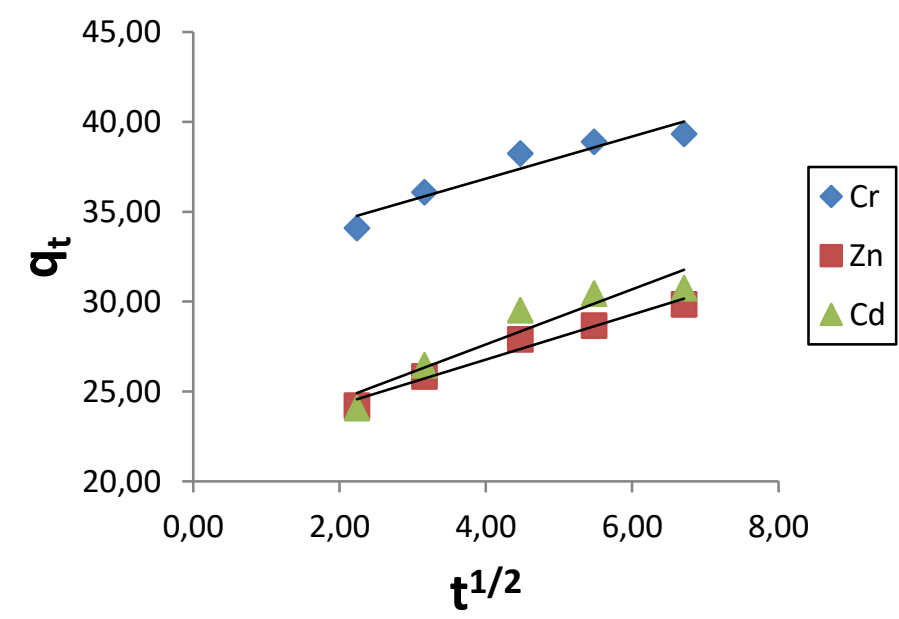

Figure 6 Intraparticle diffusion model for the adsorption of heavy metals on the HAP/CHN composite

\section{Conclusions}

In summary, synthetic composites containing HAP with CHN were prepared by combined precipitation and mixing methods, along with characterization by FTIR and SEMEDX methods. The adsorption of heavy metals on the 1:1 (wt.\%) HAP/CHN composite from aqueous media was studied using a batch adsorption system. The results revealed the benefits of the amine and hydroxyl functional groups of CHN in the composite adsorbent, 
which provided adequate and versatile adsorption for the removal of heavy-metal ions. The maximum adsorption capacities of $\mathrm{Cr}^{6+}, \mathrm{Cd}^{2+}$ and $\mathrm{Zn}^{2+}$ in batch adsorption studies were estimated as 39.3, 30.8 and $29.9 \mathrm{mg} / \mathrm{g}$, respectively. Adsorption of heavy-metal ions using the HAP/CHN composite adsorbent tended to follow the pseudo-second-order and intraparticle diffusion models. The variable structure and composition of the HAP/CHN composite, including contact time for the adsorption process revealed remarkably different adsorption properties. The modified CHN material can enhance the adsorption capacity of heavy-metal ions, along with the effects of parameters, such as temperature, $\mathrm{pH}$ and coexisting ions on the adsorption properties. Further studies are underway to gain insight into the role of competitor ions, selectivity and thermodynamics of adsorption of new nanoand micro-structured composites materials, which can be further used for industrial applications.

\section{Acknowledgements}

The authors greatly acknowledge the Kemenristek/BRIN for a research grant award through the PTUPT grant No. NKB-1733/UN2.R3.1/HKP.05.00/2019. We also thank Mr. Santoso for preparing synthetic HAP and assistance with some materials characterization.

\section{References}

Aliabadi, M., Irani. M., Ismaeili, J., Najafzade, S., 2014. Design and Evaluation of Chitosan/Hydroxyapatite Composite Nanofiber Membrane for the Removal of Heavy Metal Ions from Aqueous Solution. Journal of the Taiwan Institute of Chemical Engineers, Volume 45(2), pp. 518-526

Corami, A., Mignardi, S., Ferrini, V., 2007. Copper and Zinc Decontamination from Singleand Binary-Metal Solutions using Hydroxyapatite. Journal of Hazardous Materials, Volume 146(1-2), pp. 164-170

Dong, L., Zhu, Z., Qiu, Y., Zhao, J., 2010. Removal of Lead from Aqueous Solution by Hydroxyapatite/Magnetite Composite Adsorbent. Chemical Engineering Journal, Volume 165(3), pp. 827-834

Duan, C., Ma, T., Wang, J., Zhou, Y., 2020. Removal of Heavy Metals from Aqueous Solution using Carbon-based Adsorbents: A Review. Journal of Water Process Engineering, Volume 37, pp. 101339

Gupta, N., Kushwaha. A.K., Chattopadhyaya, M.C., 2012. Adsorptive Removal of $\mathrm{Pb}^{2+}, \mathrm{Co}^{2+}$ and $\mathrm{Ni}^{2+}$ by Hydroxyapatite/Chitosan Composite from Aqueous Solution. Journal of the Taiwan Institute of Chemical Engineers, Volume 43(1), pp. 125-131

Kousalya, G.N., Gandhi, M.R., Sundaram, S., Meenakshi, S., 2010. Synthesis of Nanohydroxyapatite Chitin/Chitosan Hybrid Biocomposites for the Removal of Fe(III). Carbohydrate Polymers, Volume 82(3), pp. 594-599

Kusrini, E., Mualim, N.M., Rahman, A., Usman, A., 2020a. Application of activated Na-zeolite as a water softening agent to remove $\mathrm{Ca}^{2+}$ and $\mathrm{Mg}^{2+}$ ions from water. AIP Conference Proceedings, Volume 2255, pp. 060012

Kusrini, E., Mualim, N.M., Usman, A., Setiawan, M.D.H., Rahman, A., 2020b. Synthesis, Characterization and Adsorption of $\mathrm{Fe}^{3+}, \mathrm{Pb}^{2+}$ and $\mathrm{Cu}^{2+}$ Cations using Na-Zeolite A Prepared from Bangka Kaolin. AIP Conference Proceedings, Volume 2255, pp. 060013

Kusrini, E., Alhamid, M.I., Widiantoro, A.B., Daud, N.Z.A., Usman, A., 2020c. Simultaneous Adsorption of Multi-lanthanides from Aqueous Silica Sand Solution using PectinActivated Carbon Composite. Arabian Journal for Science and Engineering, Volume 45, pp. 7219-7230 
Kusrini, E., Wu, S., Susanto, B.H., Lukita, M., Gozan, M., Hans, M.D., Rahman, A., Degirmenci, V., Usman, A., 2019a. Simultaneous Absorption and Adsorption Processes for Biogas Purification using $\mathrm{Ca}(\mathrm{OH})_{2}$ Solution and Activated Clinoptilolite Zeolite/Chitosan Composites. International Journal of Technology, Volume 10(6), pp. 1243-1250

Kusrini, E., Paramesti, S.N., Zulys, A, Daud, N.Z.A., Usman, A., Wilson, L.D., Sofyan, N., 2019b. Kinetics, Isotherm, Thermodynamic, and Bioperformance of Defluoridation of Water using Praseodymium-Modified Chitosan. Journal of Environmental Chemical Engineering, Volume 7(6), pp. 103498

Kusrini, E., Usman, A., Sani, F.A., Wilson, L.D., Abdullah, M.A.A., 2019c. Simultaneous Adsorption of Lanthanum and Yttrium from Aqueous Solution by Durian Rind Biosorbent. Environmental Monitoring and Assessment, Volume 191(8), pp. 488

Kusrini, E., Shiong, N.S., Harahap, Y., Yulizar, Y., Dianursanti, Arbianti, R., Pudjiastuti, A.R., 2015b. Effects of Monocarboxylic Acids and Potassium Persulfate on Preparation of Chitosan Nanoparticles. International Journal of Technology, Volume 6(1), pp. 11-21

Kusrini, E., Arbianti, R., Sofyan, N., Abdullah, M.A.A., Andriani, F., 2014. Modification of Chitosan by using Samarium for Potential Use in Drug Delivery System. Spectrochimica Acta Part A: Molecular and Biomolecular Spectroscopy, Volume 120, pp. 77-83

Kusrini, E., Sofyan, N., Nurjaya, D.M., Santoso, S., Tristantini, D., 2013. Removal of Heavy Metals from Aqueous Solution by Hydroxyapatite/Chitosan Composite. Advanced Materials Research, Volume 789, pp. 176-179

Kusrini, E., Sofyan, N., Suwartha, N., Yesya, G., Priadi, C.R., 2015a. Chitosan-Praseodymium Complex for Adsorption of Fluoride Ions from Water. Journal of Rare Earths, Volume 33(10), pp. 1104-1113

Kusrini, E., Sontang, M., 2012. Characterization of X-ray Diffraction and Electron Spin Resonance: Effects of Sintering Time and Temperature on Bovine Hydroxyapatite. Radiation Physics and Chemistry, Volume 81(2), pp. 118-125

Lanregren, S., 1889. About the Theory of So-Called Adsorption of Soluble Substances. Kungliga Svenska Vetenskapsakademiens Handlingar, Volume 24(4), pp. 1-39

Liaw, B.S., Chang, T.T., Chang, H.K., Liu, W.K., Chen, P.Y., 2020. Fish Scale-Extracted Hydroxyapatite/Chitosan Composite Scaffolds Fabricated by Freeze Casting-An Innovative Strategy for Water Treatment. Journal of Hazardous Materials, Volume 382, pp. 121082

Ngabura, M., Hussain, S.A., Ghani, W.A., Jami, M.S., Tan, Y.P., 2018. Utilization of Renewable Durian Peels for Biosorption of Zinc from Wastewater. Journal of Environmental and Chemical Engineering, Volume 6(2), pp. 2528-2539

Robati, D., 2013. Pseudo-Second-Order Kinetic Equations for Modelling Adsorption Systems for Removal of Lead Ions using Multi-Walled Carbon Nanotube. Journal of Nanostructured Chemistry, Volume 3, pp. 55

Salah, T.A., Mohammad, A.M., Hassan, M.A., El-Anadouli B.E., 2014. Development of Nanohydroxyapatite/Chitosan Composite for Cadmium Ion Removal in Wastewater Treatment. Journal of the Taiwan Institute of Chemical Engineers, Volume 45(4), pp. 1571-1577

Schmuhl, R., Krieg, H.M., Keizer, K., 2001. Adsorption of $\mathrm{Cu}(\mathrm{II})$ and $\mathrm{Cr}(\mathrm{VI})$ ions by Chitosan: Kinetics and Equilibrium Studies. Water SA, Volume 27(1), pp. 1-8

Tomczak E., 2011. Application of ANN and EA for Description of Metal Ions Sorption on Chitosan Foamed Structure-Equilibrium and Dynamics of Packed Column. Computer \& Chemical Engineering, Volume 35(2), pp. 226-235

Usman, A., Kusrini, E., Widiantoro, A.B., Hardiya, E., Abdullah, N.A., Yulizar, Y., 2018. Fabrication of Chitosan Nanoparticles Containing Samarium Ion Potentially Applicable 
for Fluorescence Detection and Energy Transfer. International Journal of Technology, Volume 9(6), pp. 1112-1120

Vieira, C.L., Sanches Neto, F.O., Carvalho-Silva, V.H, Signini, R., 2019. Design of a Polar Chitosan-type Adsorbent for Removal of $\mathrm{Cu}(\mathrm{II})$ and $\mathrm{Pb}(\mathrm{II})$ : An Experimental and DFT Viewpoint of the Complexation Process. Journal of Environmental Chemical Engineering, Volume 7(3), pp. 103070

Weber, W.J, Morris, J.C., 1963. Kinetics of Adsorption on Carbon from Solution. Journal of the Sanitary Engineering Division, Volume 89(2), pp. 31-60

Wu, F.C., Tseng, R.L., Juang, R.S., 2010. A Review and Experimental Verification of using CHNosan and its Derivatives as Adsorbents for Selected Heavy Metals. Journal of Environmental Management, Volume 91(4), pp. 798-806

Zhang, C.J., Hu, M., Ke, Q.F., Guo, C.X., Guo, Y.J., Guo, Y.P., 2020. Nacre-inspired Hydroxyapatite/Chitosan Layered Composites Effectively Remove Lead Ions in a Continuous-flow Wastewater. Journal of Hazardous Materials, Volume 386, pp. 121999

Zhang, Z., Wang, X., Wang, H., Zhao, J., 2018. Removal of Pb(II) from Aqueous Solution using Hydroxyapatite/Calcium Silicate Hydrate (HAP/C-S-H) Composite Adsorbent Prepared by a Phosphate Recovery Process. Chemical Engineering Journal, Volume 344, pp. 53-61 